\title{
Analysis of Solar Chimney Power Plants Based on the Bam's Climate
}

\author{
Amir Bagheran Sharbaf*, Ali Asghar Shojaei, Paniz Bagheran Sharbaf
}

\begin{abstract}
One of the ways to generate power from the solar energy is to use the solar chimney technology. In the present study, by examining the weather map of Iran and using GIS software for selecting the appropriate area for the power plant site, the four physical models proposed studied for the solar chimney. This study is a numerical simulation (by MATLAB) regarding four physical models of solar chimneys in the city of Bam site, in Kerman province. The difference between the four mentioned models of the solar chimney is in storage system and the use of air diffuser. The behaviors of all four models were examined according to the valid meteorological information on a specific day from the target site. According to the results of the simulation, which includes airflow speed in several internal parts of the chimney and the production capacity of each of the mentioned models, the best and most proper model of solar chimney can be selected for the studies site and a proper estimation of the final production can be obtained.
\end{abstract}

Keywords: GIS software; numerical simulation; production capacity; solar chimney power plant; wind speed

\section{INTRODUCTION}

The quantity of energy consumption has significantly increased with the advancement of technology and industrialization of countries. Increasing the capacity of power grids depends on the investment and production of new power plant units. Due to declining fossil fuel reserves and increasing air pollution and global warming, researchers are trying to replace production units based on new and renewable energy instead of conventional units. The use of solar energy as a green and sustainable energy has always attracted the attention of researchers. Solar Chimney Power Plant is one of the new projects that will always be a place for innovation and research, and so far, general research has been done on this type of technology in Iran, but unfortunately, so far, no detailed study has been done due to the weather conditions in a specific place in Iran. The first example of this power plant was established in the Manzanares region of Spain, where researchers, after conducting research on the unit and other units, have reached better and more complete results about this technology. The effective parameters in the design of the solar chimney have been studied in [1]. These studies include changing the outlet and inlet radius of the chimney [2], types of heat storage systems and its effect on the solar chimney [3] and [4], the effect of collector surface on output power [5] and the effect of collector radius and the intensity of solar radiation [6] and the study of variables to increase the outlet of the solar chimney. Research(s) has also been conducted on the cost estimate for this project in India [7, 8 and 9]. Regarding the climatic conditions of Iran, which has desired areas for the construction of this type of power plant, such new and highyield projects can be used as alternative infrastructure projects and other advantages of using this type of power plant can be applied. With a brief review of Iran's climate maps, especially in the central and eastern regions, it will be founded out that this new and clean technology is applicable there. We also consider the country's climate maps to find an ideal site over a 25 -year period in terms of cloudiness, temperature, sunlight and wind intensity for establishing a site for Solar Chimney Power Plant [10]. Unfortunately, studies on this case have rarely been done in the Iranian climate. In the present study, by examining the four physical models [11] of the solar chimney and simulating the results of the existence of each and finally the output power of each model [12], a proper result can be obtained regarding the operation of the appropriate model for the site.

\section{INVESTIGATION OF IRAN's WEATHER CONDITIONS}

With reference to the necessary factors to study the mentioned plan, it is essential to study the whole area of Iran in terms of the rate of sunlight, the duration of sunlight, the rate of cloudiness and wind conditions in the studied areas. Iran, with an area of about 1,648,591 square kilometers, is located between 25 degrees and 3 minutes to 39 degrees and 47 minutes north latitude and 44 degrees and 5 minutes to 63 degrees and 18 minutes east longitude, so in terms of receiving Solar energy is among the highest in the world. Due to this feature, it has great potential for exploiting natural resources and energies. In order to reach the best and most proper place in Iran to establish the Solar Chimney Power Plant site, we need to study the desired parameters, such as the amount of sunlight, the amount of cloudiness in the area and the intensity of the wind.

\subsection{Zoning of Iran's Regions in Terms of Solar Radiation}

Iran has a four-season climate. As observed in the Fig. 1, Iran is divided into four climatic zones on the map. The Northern Belt (Region1) has a humid and rainy climate. The western region (Region2) has a temperate and cool climate, the central and southeastern regions (Region3) have hot and dry climates and the southern belt (Region4) has a warm and humid climate.

This division can also be considered based on the intensity of the sun's radiation. Fig. 2 indicates the hourly average of solar radiation through the years 1981-2007. As shown in Fig. 2, the most sunlight radiated areas of Iran are in Region 3.

Fig. 3 indicates the average hours of solar radiation through the months of the years (1986-2005) that the region 
(3) is marked in red, which is higher than other highly sunlight radiated areas, including areas 2 and 4 which are the highest ones.

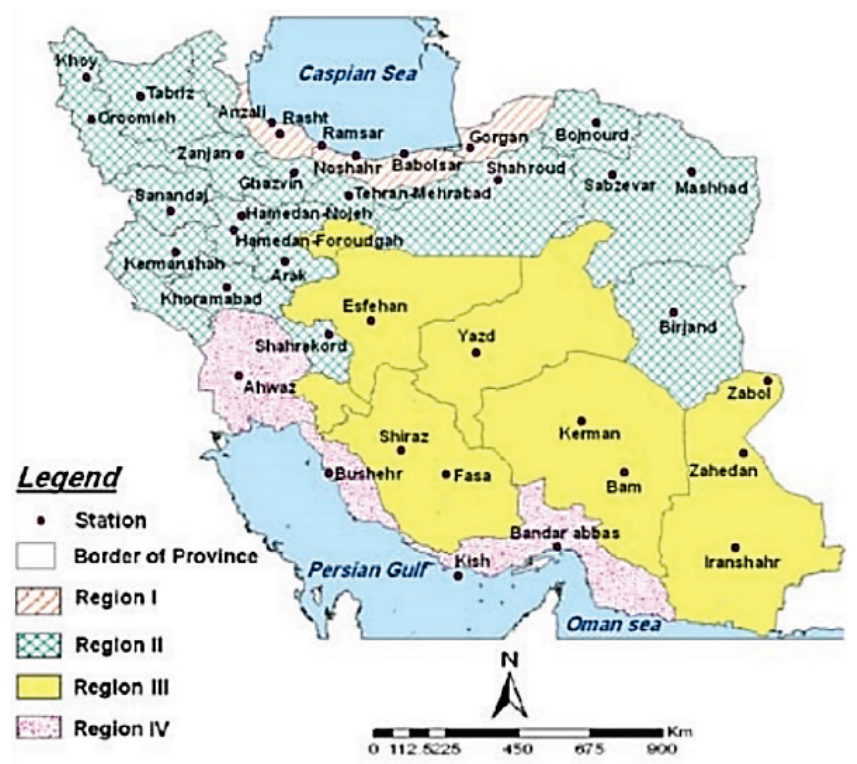

Figure 1 Climate map of Iran

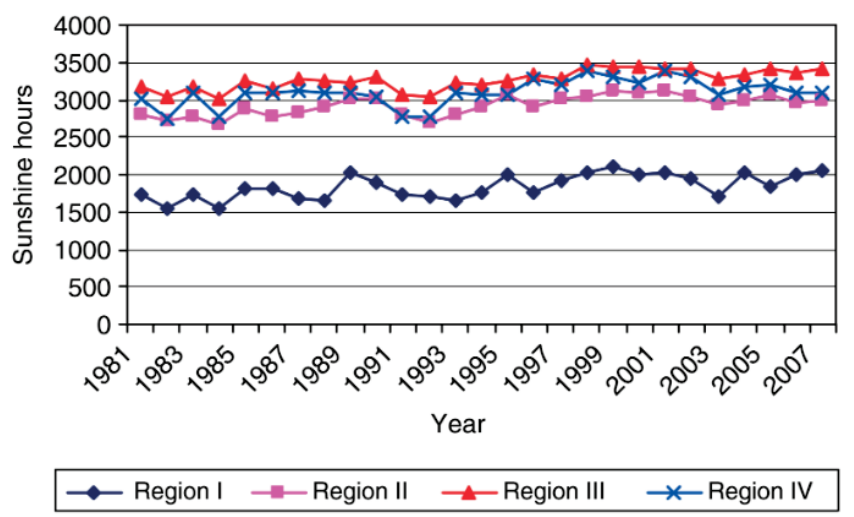

Figure 2 The average hourly sunlight through the years 1981-2007

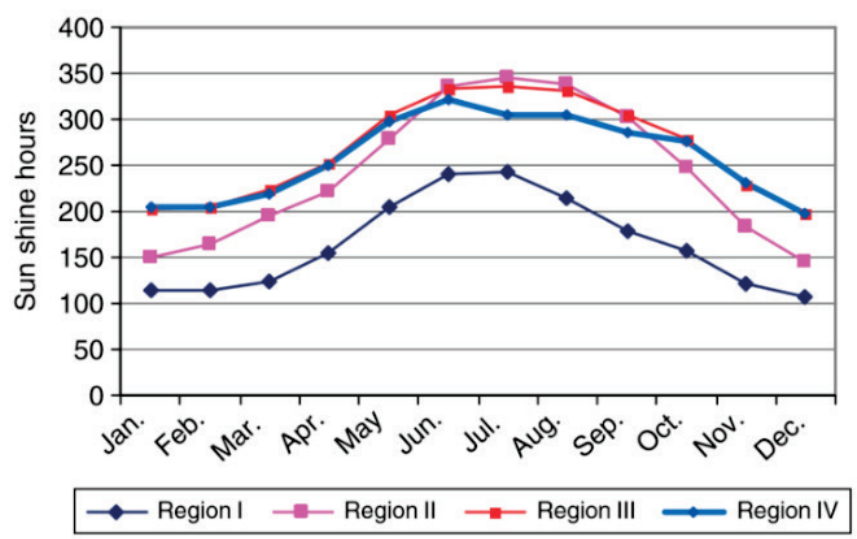

Figure 3 The average hours of solar radiation in the months of the year

\subsection{Zoning of Iran's Regions in Terms of Cloudiness}

One of the main factors in choosing the right site to establish Solar Chimney Power Plant is the low cloudiness of the region. Fig. 4 indicates the annual zoning of Iran in terms of the number of days with the least amount of cloudiness. As observed, parts of Kerman province and South Khorasan province are the most sunlight radiated regions of Iran based on the least cloudy days.

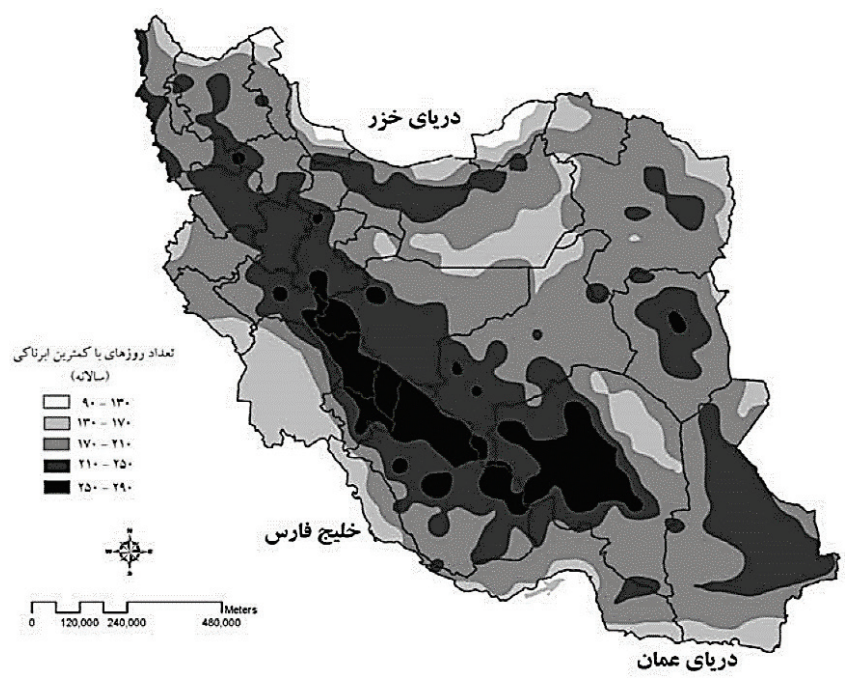

Figure 4 Annual zoning of Iran in terms of the number of days with the least amount of cloudiness

\subsection{Zoning Regions in Terms of Temperature}

Fig. 5 indicates the average temperature map of all regions of Iran. It is observed that the maximum temperature is related to the southern belt and southeastern region of Iran [16].

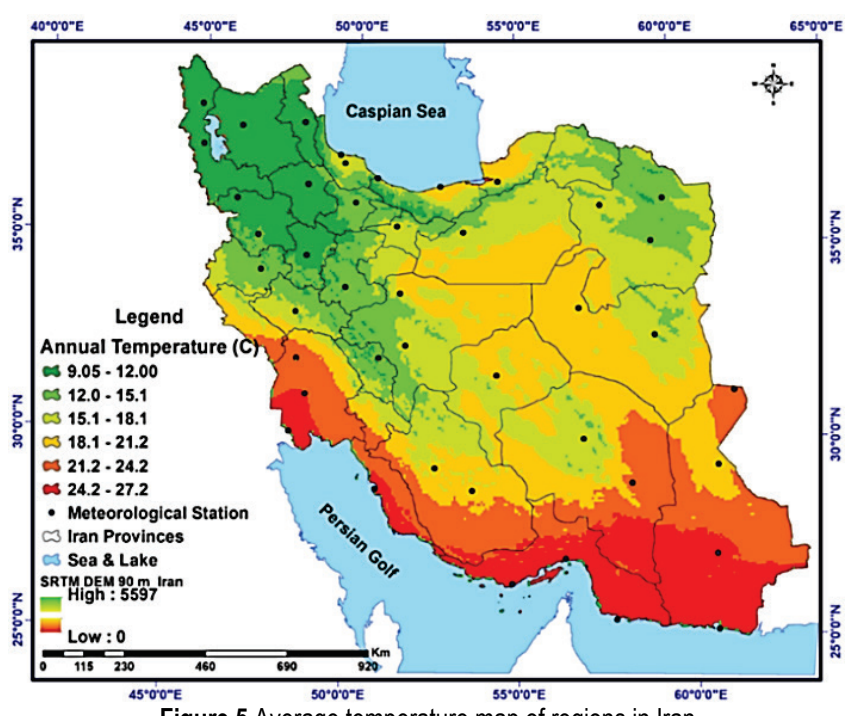

Figure 5 Average temperature map of regions in Iran

\subsection{Zoning Regions in Terms of Wind Intensity}

Toward using solar chimney technology, in addition to high solar radiation, high temperature and a dry, cloudless area, a low wind area without sandstorms is needed. The lower the wind, the more proper the site will be. Fig. 6 indicates a map of Iran in terms of average wind speed [17]. 


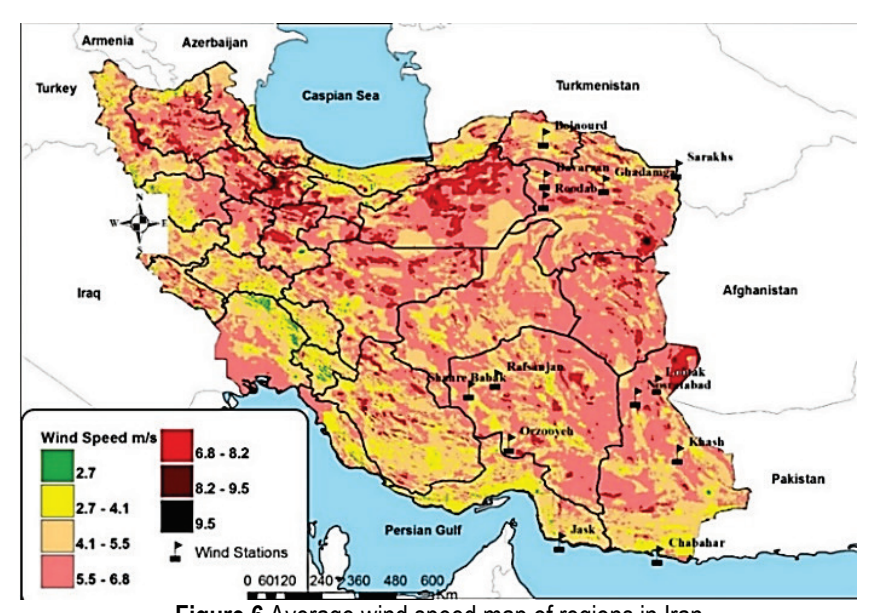

Figure 6 Average wind speed map of regions in Iran

\subsection{The Average Amount of Solar Radiation in Four Climatic Zones}

As observed in Fig. 1, four climatic regions have been identified for Iran, and Fig. 2 compares these areas based on the hours of solar radiation. Tab. 1 lists the cities in each area, and for each of these cities, the average hours of solar radiation in the seasons of spring, summer, autumn, and winter, as well as the average annual hours of solar radiation through the years of 1981 and 2007, are listed. Tab. 1 indicates that the city of Bam in Kerman province has the highest amount of radiation and Ramsar has the lowest amount of solar radiation.

Table 1 The average hours of solar radiation in spring, summer, autumn and winter, as well as the average annual hours of solar radiation through the years 1981 and 2007 for the Iranian cities

\begin{tabular}{|c|c|c|c|c|c|c|}
\hline Region & Station & Spring & Summer & Autumn & Winter & Annual \\
\hline \multirow[t]{7}{*}{1} & Anzali & 593.1 & 636.8 & $308.6^{\mathrm{a}}$ & $291.1^{\mathrm{a}}$ & 1829.7 \\
\hline & Babolsar & 616.6 & 640.0 & 388.2 & 356.1 & 2000.9 \\
\hline & Gorgan & 598.4 & 655.1 & 488.8 & 407.6 & 2150.9 \\
\hline & Noshahr & 531.5 & 525.5 & 388.7 & 350.7 & 1796.4 \\
\hline & Ramsar & $473.7^{\mathrm{b}}$ & $481.9^{\mathrm{a}}$ & 321.4 & 298.1 & $1575.1^{\mathrm{a}}$ \\
\hline & Rasht & 521.3 & 556.7 & 310.1 & 295.8 & 1684.0 \\
\hline & Avg. & 555.8 & 582.7 & 367.6 & 333.2 & 1839.5 \\
\hline \multirow[t]{19}{*}{ II } & Arak & 859.1 & 971.5 & 586.7 & 537.7 & 2955.0 \\
\hline & Birjand & 891.2 & 1027.5 & 698.1 & 610.4 & 3236.5 \\
\hline & Bojnourd & 782.1 & 937.4 & 556.5 & 451.2 & 2727.2 \\
\hline & Ghazvin & 857.3 & 1010.4 & 563.2 & 518.7 & 2949.5 \\
\hline & Hamedan- Foroudgah & 862.7 & 1001.3 & 562.4 & 507.3 & 2933.7 \\
\hline & Hamedan-Nojeh & 811.8 & 973.5 & 561.7 & 487.8 & 2834.8 \\
\hline & Kermanshah & 837.4 & 997.7 & 568.2 & 494.3 & 2897.6 \\
\hline & Khoramabad & 847.5 & 995.7 & 612.6 & 539.3 & 2995.1 \\
\hline & Khoy & 764.3 & 961.7 & 473.6 & 433.6 & 2633.2 \\
\hline & Mashhad & 832.6 & $1036.1^{\mathrm{b}}$ & 571.8 & 446.6 & 2887.2 \\
\hline & Oroomieh & 842.8 & 1020.7 & 530.9 & 481.2 & 2875.7 \\
\hline & Sabzevar & 863.9 & 1003.9 & 639.0 & 542.8 & 3049.6 \\
\hline & Sanandaj & 837.0 & 969.2 & 557.1 & 487.3 & 2850.6 \\
\hline & Shahrekord & 896.3 & 987.1 & 672.3 & 626.6 & 3182.3 \\
\hline & Shahroud & 852.3 & 967.7 & 602.1 & 562.7 & 2984.8 \\
\hline & Tabriz & 805.8 & 990.8 & 529.9 & 462.1 & 2788.6 \\
\hline & Tehran-Mehrabad & 856.5 & 989.4 & 584.7 & 546.2 & 2976.8 \\
\hline & Zanjan & 827.9 & 993.3 & 543.3 & 492.4 & 2857.0 \\
\hline & Avg. & 840.5 & 990.8 & 578.6 & 512.7 & 2923.1 \\
\hline \multirow[t]{10}{*}{ III } & Bam & 906.2 & 990.9 & 791.3 & 698.7 & $3387.0^{\mathrm{b}}$ \\
\hline & Esfehan & 911.5 & 1014.2 & 692.7 & 658.8 & 3277.2 \\
\hline & Fasa & $949.0^{\mathrm{b}}$ & 971.2 & 760.2 & 678.4 & 3358.9 \\
\hline & Iranshahr & 887.6 & 853.1 & $810.6^{\mathrm{b}}$ & $711.0^{\mathrm{b}}$ & 3262.4 \\
\hline & Kerman & 850.8 & 998.9 & 624.8 & 547.4 & 3022.0 \\
\hline & Shiraz. & 943.2 & 992.3 & 747.7 & 671.4 & 3354.7 \\
\hline & Yazd & 899.8 & 1014.7 & 711.9 & 634.1 & 3260.5 \\
\hline & Zabol & 894.3 & 923.9 & 720.4 & 628.7 & 3167.4 \\
\hline & Zahedan & 900.5 & 987.1 & 761.4 & 663.0 & 3311.9 \\
\hline & Avg. & 904.8 & 971.8 & 735.7 & 654.6 & 3266.9 \\
\hline \multirow[t]{5}{*}{ IV } & Ahwaz & 859.6 & 983.6 & 645.9 & 596.6 & 3085.7 \\
\hline & Bandar Abbas & 870.6 & 800.4 & 745.0 & 651.8 & 3060.9 \\
\hline & Bushehr & 844.9 & 923.3 & 681.5 & 601.3 & 3051.0 \\
\hline & Kish & 906.8 & 881.7 & 755.5 & 657.4 & 3201.5 \\
\hline & Average & 870.5 & 897.3 & 707.0 & 626.8 & 3099.8 \\
\hline
\end{tabular}

${ }^{\mathrm{a}}$ Lowest value in the season/annual. ${ }^{\mathrm{b}}$ Highest value in the season/annual. 


\section{SELECTING THE PROPER AREA FOR THE SITE}

Through observing the weather map of Iran and estimations in terms of temperature, solar radiation, cloudy days, the lowest amount of wind and data analyze with GIS software, one may select the most proper place for Solar Chimney Power Plant site. In keeping with the mentioned information, Region 3 is the best area in terms of solar radiation and according to Fig. 4, Kerman and Fars Provinces have the fewest cloudy days. In line with Fig. 5, the provinces of Kerman and Sistan and Baluchestan have all the required conditions based on the above results. Tab. 1 indicates that the highest hours of annual solar radiation relate to the city of Bam, which is located in Kerman province. Therefore, it can be stipulated that the city of Bam is a proper choice for the power plant site. Bam is located in the eastern part of Kerman province. The city has latitude of 29 degrees and 9 minutes north and a longitude of 58 degrees and 21 minutes east, which is 1067 meters above sea level. Fig. 7 indicates the average annual temperature in Bam. The maximum temperature of this city is 39 degrees Celsius, which is practically a proper temperature for exploiting this technology. Fig. 7 indicates the difference between the maximum and minimum temperatures of the city, which is very important and practical. The highest temperature will be on 3rd day of July, according to which Fig. 12 and Fig. 13 will be extracted [18].

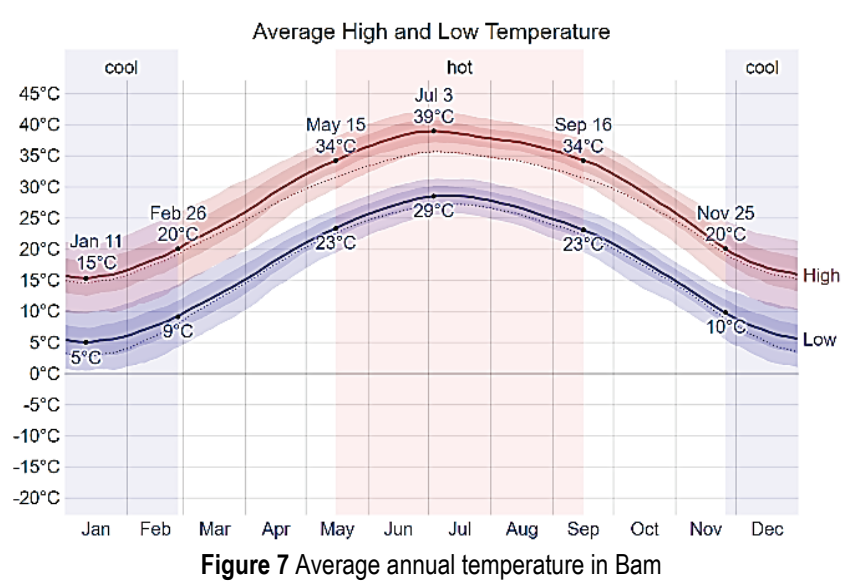

\section{THE STUDIED SOLAR CHIMNEY MODELS}

Four physical models of solar chimneys are examined in this study. For the ease of review and the same results, the collector surface and its material and the height of the chimney and its material are considered the same in all four models. The height of the chimney of all four models is 200 meters with a diameter of 10 meters. The collector has the same material and specifications, 245 meters in diameter and 2 meters above the ground. Fig. 8 indicates the first model of a solar chimney, in which water and soil are used as storage systems. In addition to using soil as a proper storage, it is covered with water to a height of $10 \mathrm{~cm}$. The water is covered with a transparent coating to prevent surface evaporation of water.

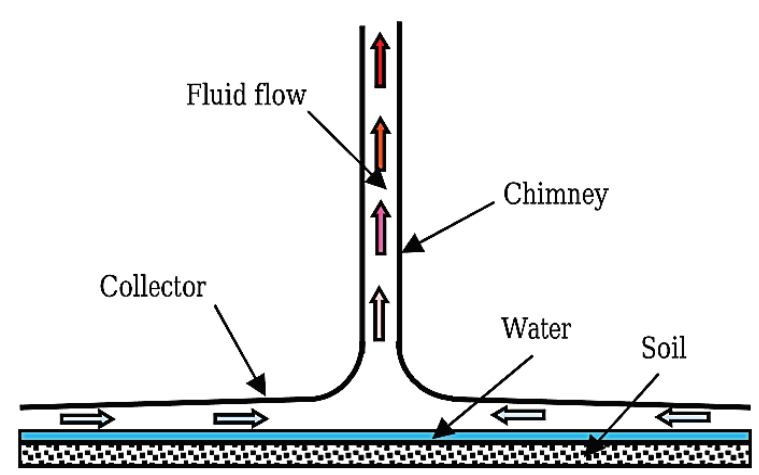

Figure 8 The first model of the solar chimney

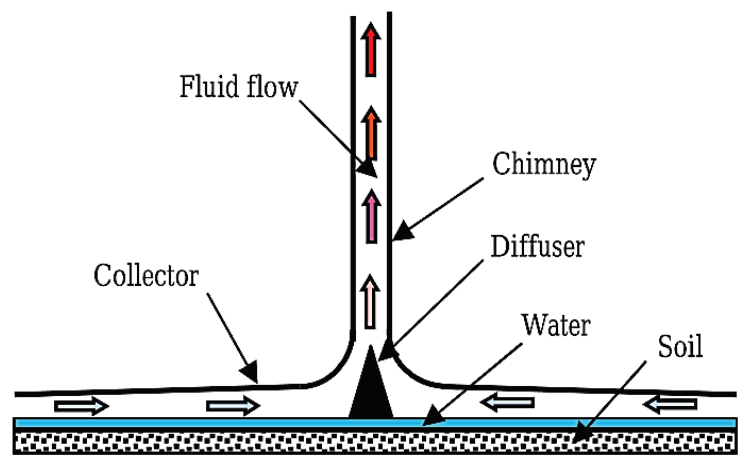

Figure 9 The second model of the solar chimney
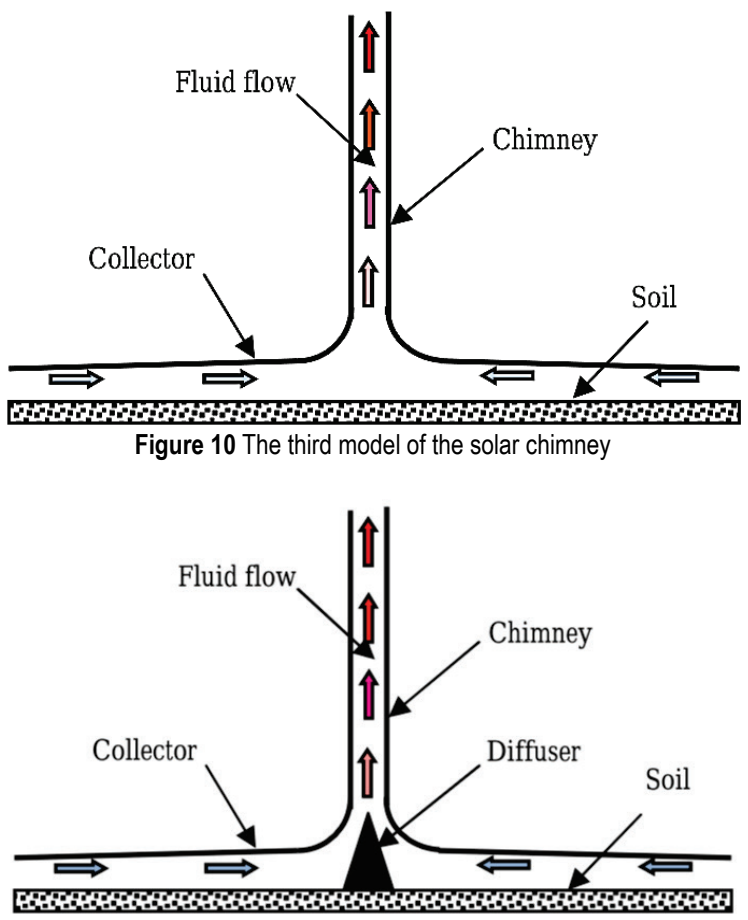

Figure 11 The fourth model of the solar chimney

Fig. 9 indicates the second model of the solar chimney that uses a diffuser at the entrance to the chimney.

Fig. 10 indicates the third model with soil storage. Fig. 11 indicates the latest model of solar chimney, having a soil storage system and a distributor at the entrance to the chimney. 


\section{EQUATIONS GOVERNING THE SOLAR CHIMNEY}

Eq. (1) shows the efficiency of the solar chimney. In Eq. (1), $Q$ is the power inlet from solar radiation based on $\mathrm{w}, p_{\text {elec }}$ is also the electric power of the solar chimney based on $\mathrm{w}, \eta_{\mathrm{t}}$ is the efficiency of the turbine based on $\mathrm{kg} / \mathrm{m}^{3} . \rho_{\mathrm{a}, \mathrm{o}}$ is the density on $\mathrm{kg} / \mathrm{m}^{3} . A_{\mathrm{t}}$ and $u_{\mathrm{t}}$ respectively are area and velocity based on $\mathrm{m}^{2}$ and $\mathrm{m} / \mathrm{s}$. $G$ is the intensity of the solar radiation is based on w/ $/ \mathrm{m}^{2}$ and $A_{\text {coll }}$ is the collector surface in $\mathrm{m}^{2}$.

$\eta=\frac{p_{\text {out }}}{p_{\text {in }}}=\frac{p_{\text {elec }}}{Q}=\frac{\frac{1}{3} \eta_{\mathrm{t}} p_{\mathrm{a}, \mathrm{o}} A_{\mathrm{t}} u_{\mathrm{t}}^{3}}{G A_{\text {coll }}}$

The maximum efficiency can be obtained from the Eq. (2). $R_{\text {coll }}$ is the radius of collector based on meter.

$\eta_{\max }=\frac{p_{\max }}{Q}=\frac{p_{\max }}{G A_{\text {coll }}}=\frac{p_{\max }}{G \pi R_{\text {coll }}^{2}}$

But the maximum power can be obtained from the Eq. (3).

$p_{\max }=\frac{p_{\mathrm{o}}}{p_{\mathrm{i}}} \cdot \frac{\pi g}{c_{p} T_{\mathrm{o}}} H R_{\mathrm{coll}}^{2} G$

In Eq. (3), $p_{\mathrm{o}}$ and $p_{\mathrm{i}}$ is the static pressure outside and inside of the chimney based on $w, c_{\mathrm{p}}$ is the specific heat capacity of the air based on $\mathrm{J} \cdot \mathrm{kg}^{-1} k^{-1} ; T_{0}$ is ambient temperature based on $k$ and $g$ is gravitational acceleration based on $\mathrm{m} / \mathrm{s}^{2}$. The electric power can be obtained Eq. (4). $\eta_{\mathrm{g}}$ is the efficiency of the generator.

$p_{\text {elec }}=\eta_{\mathrm{g}} p$

Eq. (4) can be expressed in another way [13].

$p_{\text {elec }}=\frac{2}{3}\left(\eta \frac{g H}{c_{\mathrm{p}} T_{\mathrm{o}}} A_{\text {coll }} G\right)$

In Eq. (5), $H$ is the height of the chimney tower in meters. Regarding our specifications and information about the environment and the solar chimney, it is possible to obtain maximum electrical power using Eq. (6). Using Eqs. (7), and (8), the efficiency of other parts of the chimney can be obtained $[14,15]$.

$\eta_{\text {coll }}=\frac{\dot{m} \Delta h}{G A_{\text {coll }}}$

$\eta_{\mathrm{ch}}=\frac{g H}{c_{\mathrm{p}} T_{\mathrm{o}}}$

$\eta_{\text {scpp }}=\eta_{\text {coll }} \eta_{\text {ch }} \eta_{\mathrm{T}} \eta_{\text {gen }}$
In Eq. (6), $\dot{m}$ is the mass flow rate based on $\mathrm{kg} / \mathrm{s}$ and $\Delta h$ is the airflow enthalpy $\mathrm{J} / \mathrm{kg}$. based on meter. In Eq. (8), the efficiency of the solar chimney power plant is obtained with the multiplication of the whole efficiency where $\eta_{\mathrm{ch}}$ is the efficiency of the chimney, $\eta_{\mathrm{T}}$ is the efficiency of the turbine and $\eta_{\mathrm{g}}$ is the efficiency of the generator.

\section{RESULTS FROM THE SIMULATION}

In order to perform this simulation and simplify the assumptive computations that have considered through this study, the relative input pressure of the collector is considered zero $(0)$ and the temperature of the storage system is considered constant. The chimney tower also has insulating walls. The studies were carried out based on the weather conditions in the central region of Iran, Kerman province, the city of Bam and according to the temperature and the amount of solar radiation on the third day of July. In Fig. 12, the temperature of Bam was given for the 24 hours of the third day of July [18].

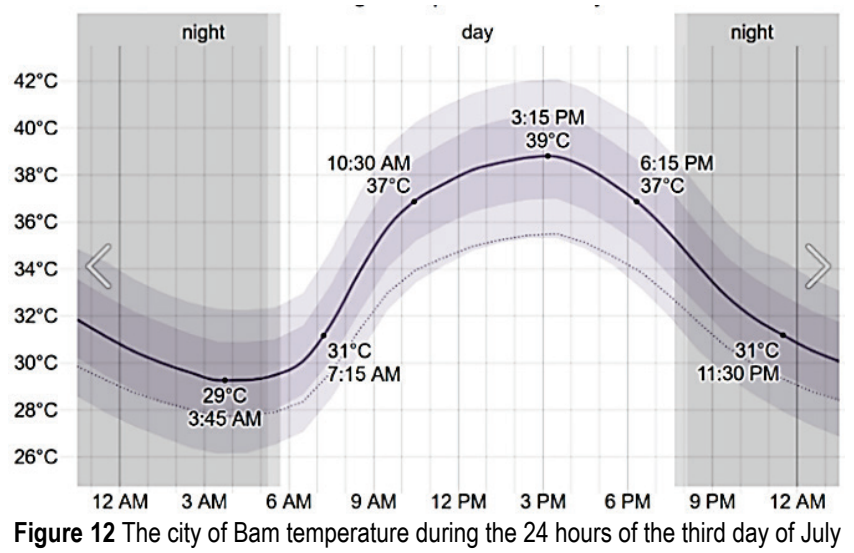

Fig. 13 indicates the amount of solar radiation for 24 hours based on kW on the third day of July [18].

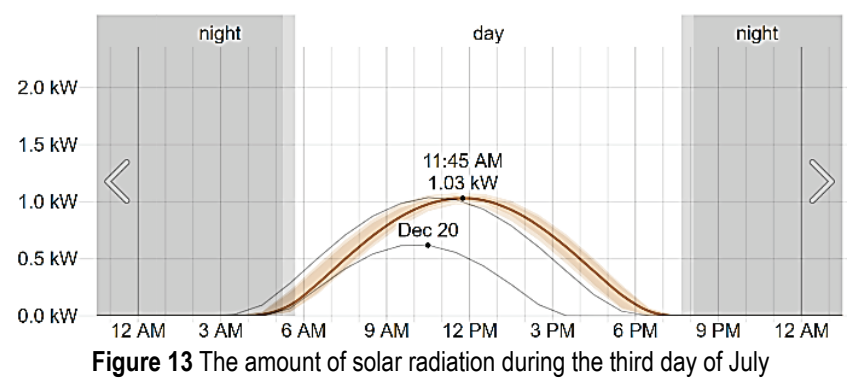

Depending on the temperature and the amount of radiation in the studied site, the necessary results can be extracted. Fig. 14 indicates the average airflow speed at the collector outlet.

Fig. 15 also indicates the average airflow speed at the chimney inlet at a height of 2 meters.

Fig. 16 indicates the average speed of airflow at the chimney inlet at a height of $6 \mathrm{~m}$ inside the chimney.

Fig. 16 indicates the average speed of airflow at the chimney inlet at a height of $6 \mathrm{~m}$ inside the chimney. Fig. 17 
indicates the airflow speed at eight meters' height of chimney.

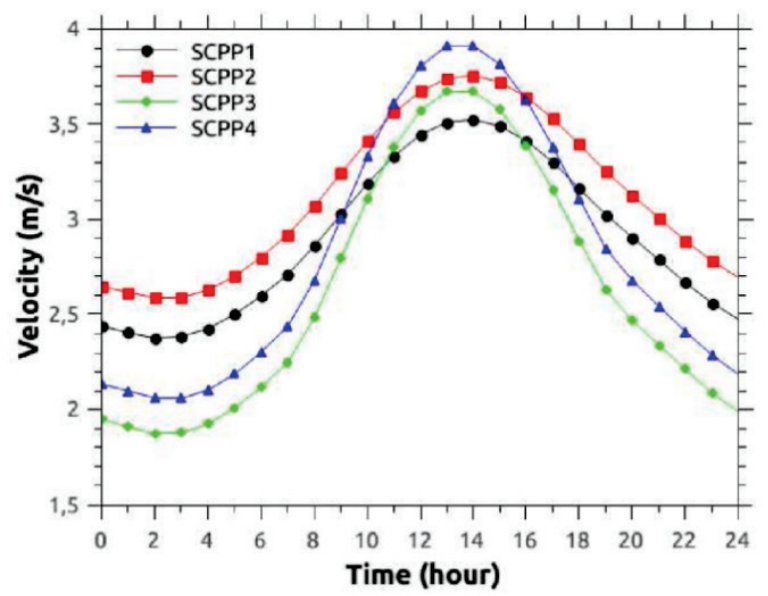

Figure 14 Airflow speed at collector outlet

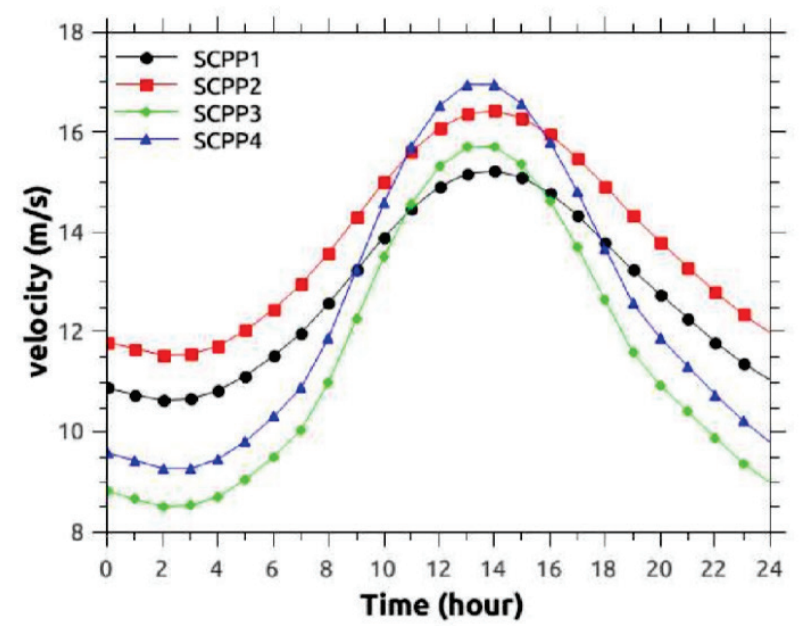

Figure 15 The airflow speed at a height of two meters in the collector

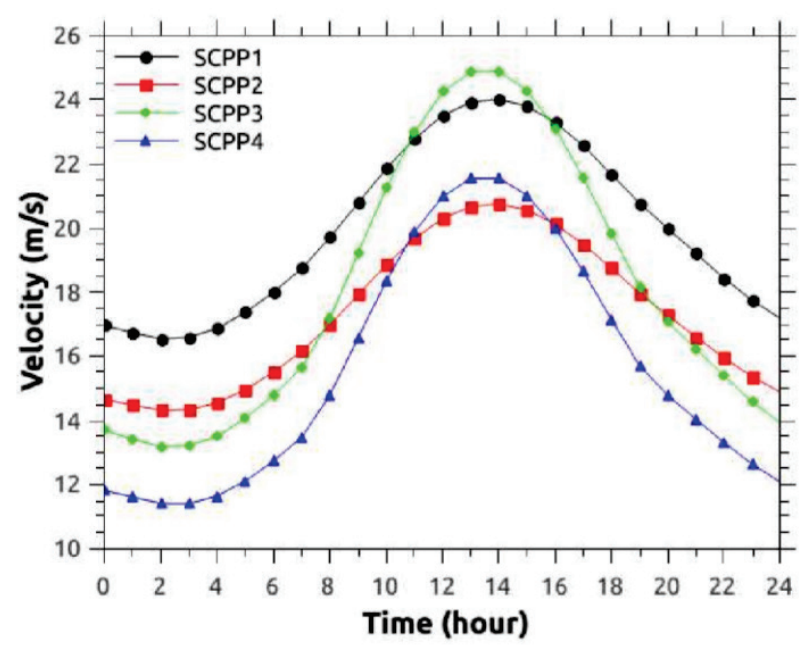

Figure 16 Airflow speed at six meters' height of collector

The results of the above figures are significant. It is obvious that the highest airflow speed occurs during solar radiation times. In models (1) and (2) where the storage is used, the average rate of airflow at sunset is much higher than in models without storage. In the case of the diffuser, which is in models 2 and 3 at the collector outlet, it increases the airflow speed at the collector outlet and the 2 meters height of the chimney. But at a height of 6 and 8 meters, the chimney has the opposite effect and reduces the speed of airflow. Another point is that during the hours when we have the highest amount of solar radiation, between 11:00 and 16:00 o'clock, in models that have a storage system (models 2 and 4), the average air speed decreases compared to similar models without a storage system.

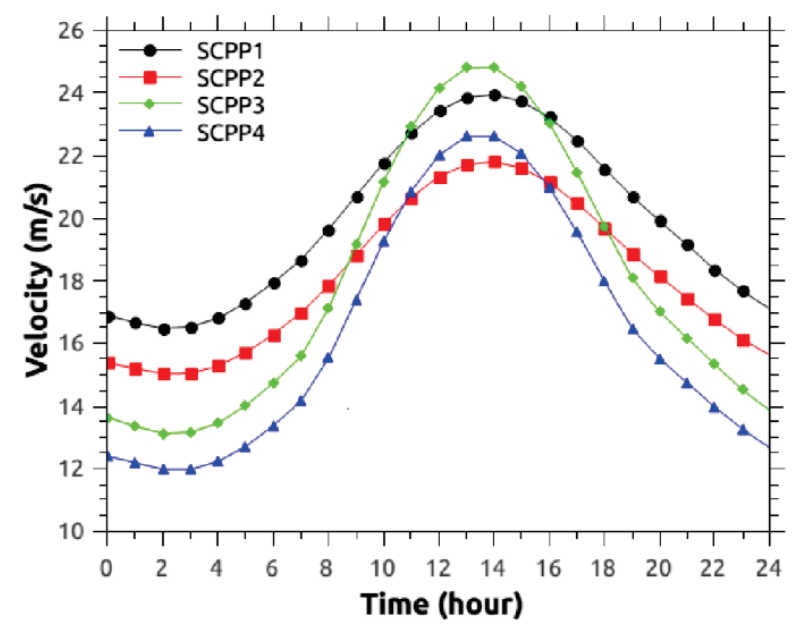

Figure 17 Airflow speed at eight meters' height of collector

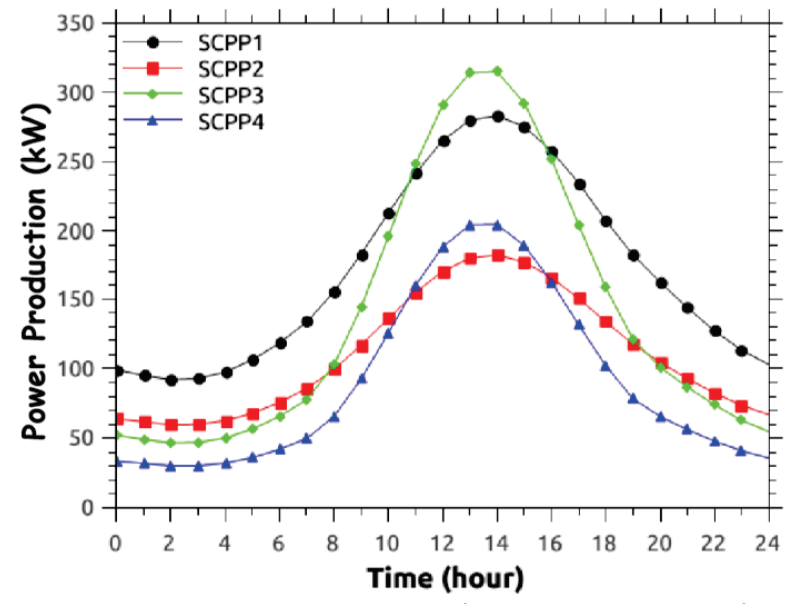

Figure 18 The average production capacity of a solar chimney in terms of kW

Fig. 18 indicates the average production capacity in $\mathrm{kW}$, based on the 24 hours of the third day of July. The maximum power output is $300 \mathrm{~kW}$, which is produced by Model 3. The second production of $260 \mathrm{~kW}$ is related to model 1 . The fourth model has about $200 \mathrm{~kW}$ in maximum production mode and $170 \mathrm{~kW}$ is the share of the fourth model. Figure 18 indicates that at sunset, models 2 and 4 that have a storage system with more production capacity than similar models without storage. It is important to note the effect of the diffuser that models without distributors (models 1 and 3) have far more power production, having more significant power than models with diffusers (models 2 and 4). The 
reason for this could be a decrease in the level of the inlet section as well as an increase in the chimney inlet, which reduces the production capacity. The use of airflow diffuser at the collector outlet at a height of 6 meters and higher heights will be efficient and will increase the airflow speed. However, at lower heights, it will have the reverse effect.

\section{CONCLUSIONS}

Numerical analysis of airflow in the case of four models of solar chimney and production capacity of each model on a specific day (July 3rd) based on annual meteorological patterns was performed on the site of the city of Bam of Kerman province. Comparing the results, it was found that models that have a heat storage system (water and soil) without an air diffuser will be more efficient and effective. The use of solar chimneys in Iran can be a proper solution to increase the capacity of the network and the use of clean and new technologies. Taking into consideration the results of the study of four models of solar chimneys, a good viewpoint is available about the use of the optimal model in the desired site. Taking into account this technology of energy production and investment in renewable energy issue, the most sunlight radiated areas can be considered as a hub for the use of this type of technology, which will not only benefit from the energy produced, but also the target site may be the research site for this technology. Many other articles have discussed the use of other benefits, including the greenhouse space under the collector, which can also be used on the site. Due to the novelty of the mentioned technology, several additional research can be done on the production costs of this technology based on the generated electric power, the study of other materials that can be used in the construction of chimneys and collectors and estimating the costs of the project implementation in terms of affordability.

\section{REFERENCES}

[1] Esfidani, M. T., Raveshi, S., Shahsavari, M., \& Sedaghat, A. (2015). Computational study on design parameters of a solar chimney. 2015 International Conference on Sustainable Mobility Applications, Renewables and Technology (SMART), Kuwait City, 1-5. https://doi.org/10.1109/SMART.2015.7399268

[2] Lebbi, M., Boualit, H., Chergui, T., Boutina, L., Bouabdallah, A., \& Oualli, H. (2015). Tower outlet/inlet radii ratio effects on the turbulent flow control in a solar chimney. IREC2015 - the Sixth International Renewable Energy Congress, Sousse, 1-6. https://doi.org/10.1109/IREC.2015.7110859

[3] Hu, S. \& Leung, D. Y. C. (2016). Impact of Guide Wall Geometry on the Power Output of a Solar Chimney Power Plant. Energy Procedia, 88, 414-421. https://doi.org/10.1016/j.egypro.2016.06.015

[4] Huang, H., Li, G., \& Zhang, H. (2010). Experimental Performance of a Solar Collector in Solar Chimney Power Plant System. 2010 International Conference on Electrical and Control Engineering, Wuhan, 3718-3721. https://doi.org/10.1109/iCECE.2010.907

[5] Chikere, O., Alkayiem, H. H., \& Karim, Z. A. A. (2011). Thermal field study and analysis in hybrid solar flue gas chimney power plant. 2011 National Postgraduate Conference, Kuala Lumpur, 1-6.
https://doi.org/10.1109/NatPC.2011.6136401

[6] Atia, H., Snoussi, A., Benbrahim, A., Ilinca, A., \& Boukchina, R. (2016). Energetic and exergetic evaluation of conventional and sloped solar chimney power plants. The $7^{\text {th }}$ International Renewable Energy Congress (IREC), Hammamet, 1-6. https://doi.org/10.1109//REC.2016.7478888

[7] Akhtar, Z. \& Rao, K. V. S. (2016). Estimation of levelized electricity cost of solar chimney power plant in India by using approximate cost model of Pretorius and Kroger. International Conference on Energy Efficient Technologies for Sustainability (ICEETS), Nagercoil, 276-279. https://doi.org/10.1109/ICEETS.2016.7582940

[8] Akhtar, Z. \& Rao, K. V. S. (2015). Effect of collector efficiency on levelized electricity cost of $200 \mathrm{MW}$ solar chimney power plant in India,. International Conference on Technologies for Sustainable Development (ICTSD), Mumbai, 1-6. https://doi.org/10.1109/ICTSD.2015.7095908

[9] Akhtar, Z. \& Rao, K. V. S. (2014). Study of economic viability of $200 \mathrm{MW}$ solar chimney power plant in Rajasthan, India. The $1^{\text {st }}$ International Conference on Non Conventional Energy (ICONCE 2014), Kalyani, 84-88. https://doi.org/10.1109/ICONCE.2014.6808689

[10] Mokrani, O. B. E., Sellami, M. H., Ouahrani, M. R., \& Segni, L. (2018). Experimental Investigation on The effects of opening areas on solar chimney performance. International Conference on Communications and Electrical Engineering (ICCEE), El Oued, Algeria, 1-5. https://doi.org/10.1109/CCEE.2018.8634539

[11] El-Rab, M. G., Ramadan, M., \& Khaled, M. (2014). Thermodynamic analysis of power generation from solar chimney. International Conference on Renewable Energies for Developing Countries, Beirut, 29-33. https://doi.org/10.1109/REDEC.2014.7038526

[12] Bayeh, C. Z. \& Moubayed, N. (2014). Comparison between PV farm, solar chimney and CSP tower in Lebanon: Economical study for $100 \mathrm{MW}$ power plant. International Conference on Renewable Energies for Developing Countries, Beirut, 205210. https://doi.org/10.1109/REDEC.2014.7038557

[13] Hamzeh, A. \& Fariborz, A. (2017). Mapping thermal comfort in Iran based on geostatistical methods and bioclimatic indices. Arabian Journal of Geosciences, 10. https://doi.org/10.1007/s12517-017-3129-3

[14] Satkin, M., Noorollahi, Y., Abbaspour, M., \& Yousefi, H. (2014). Multi criteria site selection model for wind-compressed air energy storage power plants in Iran. Renewable and Sustainable Energy Reviews, 32, 579-590. https://doi.org/10.1016/j.rser.2014.01.054

[15] Fanlong, M., Tingzhen, M., \& Yuan, P. (2011). A Method of Decreasing Power Output Fluctuation of Solar Chimney Power Generating Systems. Third International Conference on Measuring Technology and Mechatronics Automation, Shangshai, 114-118. https://doi.org/10.1109/ICMTMA.2011.34

[16] Cervone, A., Zaccagnini Romito, D., \& Santini, E. (2011). Design of solar chimney power plant for Mediterranean countries. International Conference on Clean Electrical Power (ICCEP), Ischia, 480-484. https://doi.org/10.1109//CCEP.2011.6036295

[17] Chergui, T., Bouhadjar, A., Boualit, A., Lebbi, M., Bonoutina L., \& Larbi, S. (2015). Improved thermo-hydrodynamic field quality in the solar chimneys. IREC2015 - the Sixth International Renewable Energy Congress, Sousse, 1-6. https://doi.org/10.1109/IREC.2015.7110972

[18] Cedar Lake Ventures, Inc. Reporter of the typical weather. Historical hourly weather reports and model reconstructions from January 1, 1980 to December 31, 2016. 


\section{Authors' contact:}

Amir Bagheran Sharbaf, MEng

(Corresponding author)

Department of Electrical Engineering, Azad University,

Adib Blvd, 9319774446 Neyshabur, Khorasan Razavi, Iran

Tell: +14388850087

E-mail: amir.bagheran@gmail.com

Ali Asghar Shojaei, $\mathrm{PhD}$ - Assistant Professor

Department of Electrical Engineering, Azad University,

Adib Blvd, 9319774446 Neyshabur, Khorasan Razavi, Iran

Tell: +14388850087

E-mail: amir.bagheran@gmail.com

Paniz Bagheran Sharbaf, MEng

Department of Architecture and Architectural Engineering, Azad University,

Pazhuhesh Blvd, 9319774446 Neyshabur, Khorasan Razavi, Iran

Tell: +989155092755

E-mail: paniz.bagheran@yahoo.com 